\title{
Biological control of golden apple snail, Pomacea canaliculata by Chinese soft- shelled turtle, Pelodiscus sinensis in the wild rice, Zizania latifolia field
}

\author{
Shengzhang Dong ${ }^{1}$, Guowan Zheng ${ }^{1}$, Xiaoping $\mathrm{Yu}^{1 *}$, Changhuan $\mathrm{Fu}^{2}$
}

\author{
${ }^{1}$ China Jiliang University/College of Life Sciences - Zhejiang \\ Provincial Key Lab. of Biometrology and Inspection \& \\ Quarantine Technique, Hangzhou 310018, China. \\ 2Inst. of Agricultural Research of Yuyao, Yuyao 315400, \\ China. \\ *Corresponding author <yxp@cjlu.edu.cn>
}

Edited by: Leonardo Oliveira Medici

Received February 25, 2011

Accepted May 18, 2011

\begin{abstract}
The wild rice, Zizania latifolia Turcz, used to be one of the important aquatic vegetables cultivated in China. Recently, the golden apple snail - GAS (Pomacea canaliculata (Lamarck)) was found to be a major invasive pest attacking $Z$. latifolia. To control efficiently GAS, predation by the Chinese soft-shelled turtles (Pelodiscus sinensis) on GAS was evaluated in laboratory and field trials. $P$. sinensis had a strong predatory capacity and selectivity for GAS both in laboratory and field conditions. All the sizes of $P$. sinensis prefer to capture smaller snails. The optimum number of $P$. sinensis released in $Z$. latifolia field was dependent on the density of over-wintered GAS, and varied between 30 and 50 turtles per $666.7 \mathrm{~m}^{2}$. The number of GAS declined in the fields with turtles as compared to turtle-free field. A pattern of releasing $P$. sinensis in Z. latifolia fields was developed and widely adopted by farmers because of much more benefit besides biologically controlling GAS.

Keywords: invasive pest, predatory capacity, turtles, snails
\end{abstract}

\section{Introduction}

The golden apple snail (GAS), Pomacea canaliculata (Lamarck), native to South America, now is a major rice exotic invasive pest in Asia (Mochida, 1991; Halwart, 1994). The yield loss caused by GAS in rice was estimated varying from $5 \%$ to $100 \%$ depending on locality and the level of infestation in most Asian countries (Halwart, 1994; Naylor, 1996). In China, GAS was first introduced into Guangdong province in 1981and became a serious pest of rice since 1984 (Halwart, 1994). The first record for GAS infestation on rice and Zizania latifolia in Yuyao City of Zhejiang province was found in 2002, and became a serious pest in rice and Z. latifolia fields in 2004 (Pan et al., 2008). Z. latifolia, is one of the most important aquatic and economic vegetable crops cultivated in the Southeast China since ancient time (Guo, 2007). Nowadays, around 100 thousands hectares of $Z$. latifolia were planted in more than ten provinces in China (Chen, 1991; Zhai et al., 2001).

Numerous measures have been taken to control GAS, in Z. latifolia fields. The molluscicide was usually used to kill GAS with a serious environmental and human health consequence, and the hand-picking was proved to be a time-consuming work (Yu et al., 2001; Chen et al., 2003). Thus, local farmers did not adopt these methods extensively for GAS control. Recently, the biological control was applied to suppress the occurrence of GAS by releasing biological agents such as fishes and ducks in crop fields. However, due to the low efficiency of fishes and ducks, especially for controlling the adult GAS (Yoshie and Yusa, 2008), the Chinese soft-shelled turtle (Pelodiscus sinensis), was tentatively selected as a new biological agent to control GAS in Z. latifolia field (Zheng et al., 2005). P. sinensis is widely distributed in Eastern Asia and usually take up $4 \sim 6$ years to reach sexual maturity adulthood. $P$. sinensis consumes insect larvae, small fish, small aquatic animals and seeds of marsh plants (Nuangsaeng and Boonyaratapalin, 2001). Furthermore, $P$. sinensis is of high commercial value and is commonly cultured in Malaysia, Indonesia and China for food consumption (Jia et al., 2005). The objective of this study is to quantify the role of $P$. sinensis in biologically controlling GAS in $Z$. latifolia field.

\section{Materials and Methods}

All tested GAS were collected semimonthly from Z. latifolia fields located in Yuyao City (E 121 ${ }^{\circ} 10^{\prime}, \mathrm{N}$ $\left.30^{\circ} 02^{\prime}\right)$, Zhejiang province, China. The laboratory population of GAS was mass-reared in greenhouse continuously at $25 \pm 2^{\circ} \mathrm{C}$. New-hatched snails were maintained on carp food, and adult snails were reared on the wild rice shoots. The tested Chinese soft-shelled turtles were provided by the local fish farmers in Yuyao City. In this study, the wild rice variety Zheda Jiaobai, was planted in each spring and harvested twice in the fall and the following summer.

The prey-predator relationship between snails and turtle was studied in the aquarium with an arena of $\mathrm{L} 75 \mathrm{~cm} \times \mathrm{W} 60 \mathrm{~cm} \times \mathrm{H} 75 \mathrm{~cm}$. The aquarium was filled with tap water to a depth of $30 \mathrm{~cm}$, and one turtle was placed in each aquarium. The tested GAS was divided into four classes in this study according to their body weight: Class I, < 0.3 g; Class II, $0.3 \sim 1.5$ g; Class III, $1.5 \sim 6.5 \mathrm{~g}$; Class IV, $6.5 \sim 70 \mathrm{~g}$. Class I to Class III correspond to young snails, and Class IV corresponds to adult snails. The tested turtles were also divided into three classes: juvenile (50 $250 \mathrm{~g}$ ), developing turtle (250 $500 \mathrm{~g}$ ) and developed turtles (500 $750 \mathrm{~g}$ ). To balance the encounter probability of turtle to snails with various sizes in the tested arena, the combination of different classes of snails was arranged in each treatment. In choice trials, a mixture of 60 Class I, 40 Class II, 20 
Class III and 10 Class IV snails were placed in the same aquarium. However, in no-choice trials, 120 Class I, 60 Class II, 20 Class III or 10 Class IV snails were placed in each aquarium. In each aquarium, one turtle was released for the feeding test, and all treatments were replicated 4 times. After 5 days, all the snails were collected from the aquaria and the number of snails consumed by the turtle was calculated by subtracting the number of the remaining snails from the initial number placed in the aquarium. The snails were replenished to the initial quantity after recording. The procedure was repeated until four replicates were obtained.

Four randomized experimental plots $(3 \mathrm{~m}$ wide and $3 \mathrm{~m}$ long) were set in $Z$. latifoliafield, and 18 seedlings of $Z$. latifolia were planted in each plot. The plots were enclosed with one-meter-high color-coated steel-tile fence. Two individuals of $P$. sinensis with a weight of about 450 $\mathrm{g}$ were released in each plot. A mixture of 360 Class I, 240 Class II, 120 Class III and 60 Class IV snails were released in each plot in Jun. 2006. The number of GAS consumed by $P$. sinensis was counted by subtracting the remaining GAS from the initial number placed in the plots 15 days later.

Experimental trials were conducted in Z. latifolia field located in GAS heavy infested areas in Yuyao Cityin 2006. The wild rice variety 'Zheda Jiaobai' was planted in the density of $50 \mathrm{~cm} \times 100 \mathrm{~cm}$ in field on Mar.2006. Two or four ditches of about $80 \mathrm{~cm}$ width and $50 \mathrm{~cm}$ depth along the field were dug to offer turtles a refuge area during farming and high temperature in summer. Besides, $6 \sim 8$ mounds of soil per $667 \mathrm{~m}^{2}$ were constructed for turtle rest in the middle of experimental fields, accounting for $5 \sim 10 \%$ area of the field. The fields were enclosed with $1 \mathrm{~m}$-high color-coated steel-tile fence to prevent the escape of turtles (Figure 1).

A field trial was conducted in four fields (field I, II, III and IV), and each field was about $1067 \mathrm{~m}^{2}$. Fields I and II were two adjacent areas with a high density (about 1,100 Class IV overwintered snails and 2,000 egg masses) of GAS, and moderate densities (about 330 Class IV over-wintered snails and 600 egg masses) of GAS were recorded in both fields III and IV. $P$. sinensis was released into the Fields II and IV in June 4, 2006, and Field I and Field III were turtle-free as control. Fifty-five and sixtyfive turtles were respectively released into Fields II and

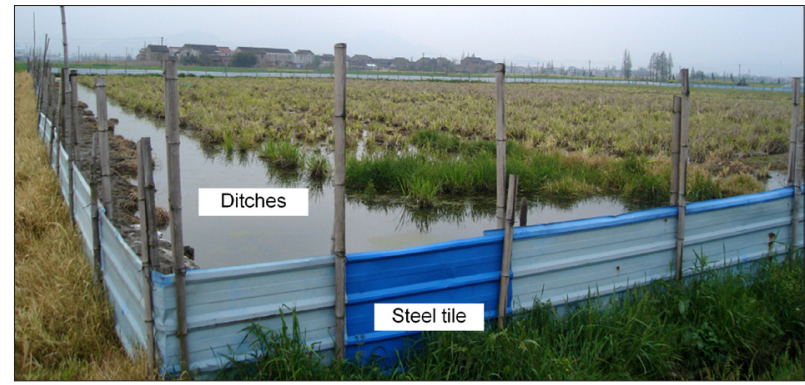

Figure 1 - The fences designed to enclose Chinese soft-shelled turtle Pelodiscus sinensis in the field with wild rice Zizania latifolia.
IV, according to the number of GAS in both fields, corresponding to 30 to 50 turtles per $667 \mathrm{~m}^{2}$, respectively.

To estimate the actual density of GAS in Z. latifolia field, snails were sampled in five $15 \mathrm{~m}^{2}$ quadrats in each filed. The number of adult and young snails was recorded every 15 days until the end of experiment. The number of egg masses on each plant was also counted every 15 days, and ten plants were selected randomly in each field.

All statistical analyses were done using the DPS package (version 8.01 for windows) (Tang and Feng, 2007). To analyze the predatory capacity of different Class of $P$. sinensis on GAS in both choice and no-choice trials, data were subjected to one-way analyses of variance (ANOVA) with repeated measures and Tukey's multiple comparison methods. The number of GAS consumed by $P$. sinensis in aquarium and field was compared using two-way ANOVA. Data for snail egg masses in turtle-released fields and control fields at the same stage were compared by Student- $t$ test. All tests were considered at $p \leq 0.05$.

\section{Results}

When the turtles were provided with only one Class of snails, the predatory capacity in a decreasing order was developed turtles $>$ developing turtles $>$ juvenile turtles (Table 1). However, there was no difference of predatory capacity on GAS between developing and developed turtles, except for that on Class IV snails.

When provided four Classes of GAS in the same arena of aquarium, the juvenile turtles preferred to eat young snails (Class I and Class II), and only $3.4 \%$ Class III snails in total snails were attacked and Class IV was not consumed. For adult turtles, all classes of GAS can be consumed when provided with a mixture of four Classes of snails. The developing turtles had a higher predatory capacity of Class I and II snails than developed turtles, while the developed turtles showed a higher predatory capacity of Class III and IV snails, which occupied 11.8 $\%$ in total snails. For Class IV snails, there was no difference of predatory capacity between developing and developed turtles. Therefore, it was concluded that the turtle's predatory selectivity for GAS in a decreasing order was juvenile turtles > developing turtles > developed turtles, which was opposite to the order of predatory capacity. To balance the predatory capacity and selectivity of $P$. sinensis on GAS, the developing turtles were recommended for the field trials.

$P$. sinensis also preferred to prey young GAS in field trials. Almost all GAS in Class I and II were consumed by $P$. sinensis after 15 days, but the numbers of GAS in Class III and Class IV consumed by $P$. sinensis were 10.89 \pm 1.39 and $3.28 \pm 0.57$ per 5 days. It indicated more GAS in field trials were consumed by $P$. sinensis than those in the arena of aquaria $(F=4.8530, \mathrm{df}=1, p=$ 0.0311 , for Class III; $F=3,423$, df $=1, p=0.002$, for Class IV). 
Table 1 - Golden apple snails (GAS) consumed by turtles Pelodiscus sinensis in no-choice and choice trials, under laboratory conditions.

\begin{tabular}{lcrcc}
\hline \multirow{2}{*}{ Treatment } & & \multicolumn{3}{c}{ No. of GAS consumed by different classes of $P$. sinensis } \\
\cline { 3 - 5 } & I & Juvenile turtles & Developing turtles & Developed turtles \\
\hline \multirow{2}{*}{ No-choice trial } & II & $47.6 \pm 3.28 \mathrm{~b}$ & $107.29 \pm 9.25 \mathrm{a}$ & $115.5 \pm 10.85 \mathrm{a}$ \\
(one class of GAS in one & III & $7.5 \pm 4.16 \mathrm{~b}$ & $91.82 \pm 8.55 \mathrm{a}$ & $114.35 \pm 11.42 \mathrm{a}$ \\
arena) & IV & $1.50 \pm 0.50 \mathrm{~b}$ & $12.88 \pm 1.01 \mathrm{a}$ & $16.65 \pm 1.26 \mathrm{a}$ \\
& I & $26.12 \pm 2.16 \mathrm{~b}$ & $3.24 \pm 0.59 \mathrm{~b}$ & $5.65 \pm 1.18 \mathrm{a}$ \\
Choice trial & II & $30.2 \pm 2.89 \mathrm{a}$ & $32.6 \pm 2.87 \mathrm{a}$ & $28.6 \pm 2.45 \mathrm{~b}$ \\
(four different classes of & III & $1.98 \pm 0.28 \mathrm{c}$ & $33.5 \pm 3.21 \mathrm{a}$ & $26.8 \pm 2.62 \mathrm{a}$ \\
GAS in one arena) & IV & 0 & $6.8 \pm 0.28 \mathrm{~b}$ & $9.34 \pm 0.83 \mathrm{a}$ \\
& & $2.1 \pm 0.21 \mathrm{a}$ & $2.84 \pm 0.56 \mathrm{a}$ \\
\hline
\end{tabular}

Note: Snails classes: I $=0 \sim 0.3 \mathrm{~g} ; \mathrm{II}=0.3 \sim 1.5 \mathrm{~g}$; III = 1.5 6.5 g; IV = 6.5 70 g. Turtle classes: Juvenile turtles $=50 \sim 250 \mathrm{~g}$; Developing turtles $=250 \sim$ $500 \mathrm{~g}$; Developed turtles=500 $750 \mathrm{~g}$. Different letters in the same row indicate difference among means (one-factor ANOVA and Tukey's multiple comparisons, $p \leq 0.05)$.
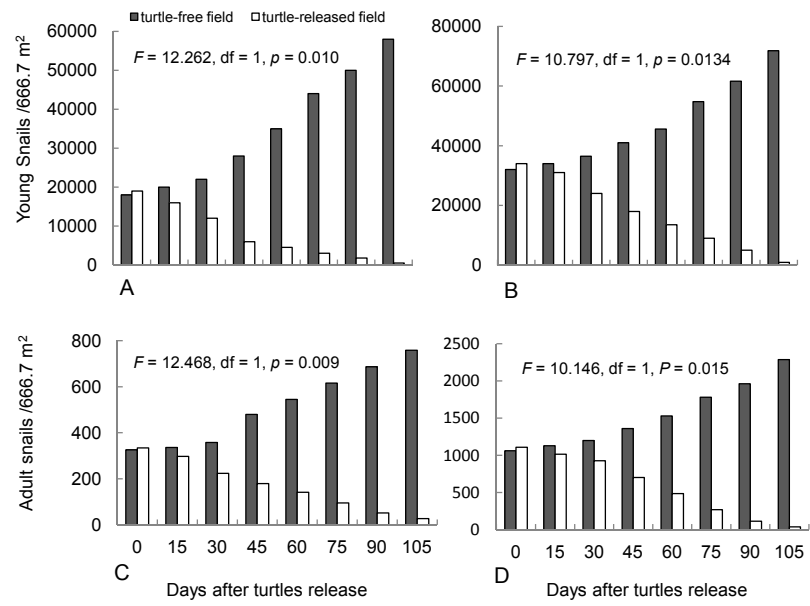

Figure 2 - Golden apple snails (GAS) consumed by Chinese softshelled turtle in moderately snail-infested fields (Figure 2A for young snails and Figure $2 \mathrm{C}$ for adult snails) and heavy snail-infested fields (Figure 2B for young snails and Figure 2D for adult snails). The turtles were released on 04 Jun. 2006. The number of snails in turtle-released field and turtle-free field were compared using twoway analyses of variance (ANOVA) without replications. The tests were considered at $p \leq 0.05$.

In the turtle-free field, the number of GAS increased rapidly, especially the young snails. In the turtlereleased field, the number of both young and adult snails declined as compared to the turtle-free field (Figure 2). During first 15 days, after turtles were released, the number of both young and adult GAS hardly decreased, while the number of GAS in both tested snail-infested fields was effectively suppressed within 90 days after turtles were released. Furthermore, the number of egg masses laid by GAS was also declined 30 days day after turtles released as compared to turtle-free field (Figure 3). By the end of experiment, the new egg masses were hardly found in the turtle-released fields.

\section{Discussion}

The Chinese soft-shelled turtle, $P$. sinensis, has a strong predatory capacity for controlling GAS both under

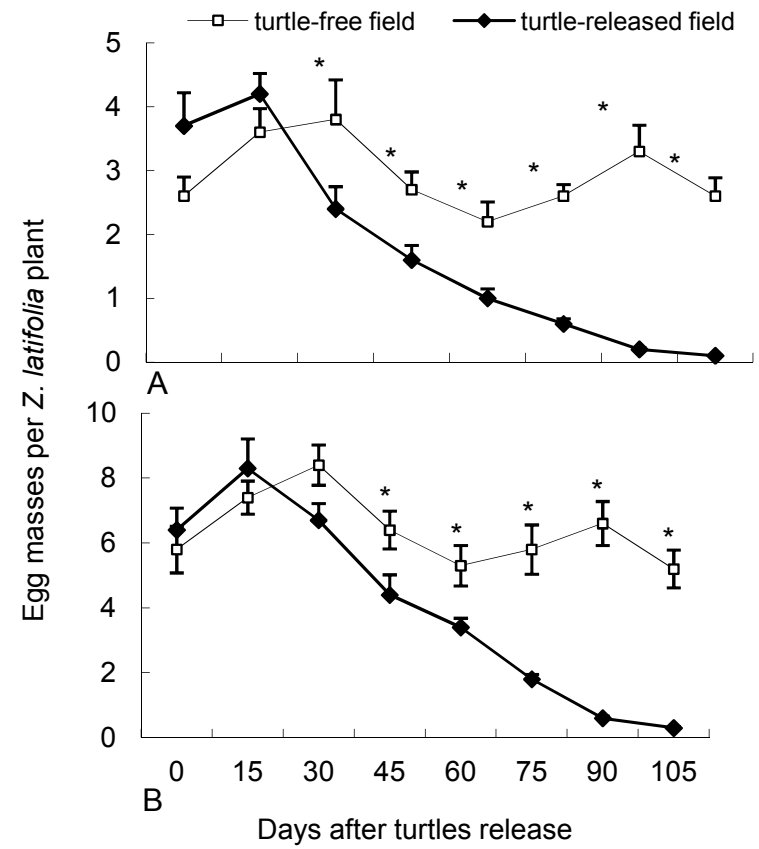

Figure 3 - Egg masses on each Zizania latifolia plant in moderately snail-infested fields (upper) and heavy snail-infested fields (below). The Chinese soft-shelled turtles Pelodiscus sinensis were released on 04 Jun. 2006. The data expressed as Means \pm standard error $(n=10)$. At the same stage, the data with asterisks are different $\left({ }^{*} p<0.05\right)$ by Student's t-test.

laboratory and field conditions. By the use of $P$. sinensis, a method for biologically controlling GAS was developed in Z. latifolia field. As far as we know, it is the first report to use $P$. sinensis for biological control of GAS in wild rice fields or paddy fields. During controlling GAS, a pattern of stocking $P$. sinensis in $Z$. latifolia field was developed and was adopted extensively by local farmers because they can benefit from marketing both $Z$. latifolia and $P$. sinensis. Meanwhile, the cost of a large amount of chemical molluscicides was also saved. By releasing turtles, the yield of $Z$. latifolia shoot increased up to 1500 $\sim 2000 \mathrm{~kg}$ per $667 \mathrm{~m}^{2}$ as compared to the turtle-free field without use of synthetic molluscicides, and the income per $667 \mathrm{~m}^{2}$ increased to 800 1000 US Dollars. Further- 
more, although there was no outbreak of GAS both in 2008 and 2009, the local farmers continue to release $P$. sinensis in $Z$. latifolia fields for both economic and biological control reasons.

There are many animals known to feed on GAS or their eggs, including fish, birds, rats, lizards, frogs, toads, beetles and ants (Cowie, 2002). The turtles, including Trachemysscripta, Chinemysreevesii, Mauremys japonica, were first reported to have the ability to consume GAS in aquaria by Yusa et al. (2006). In the present study, predatory capacity of turtle, $P$. sinensis, was also conformed both in laboratory and field conditions, including preference to younger snails and strong predatory ability. The feeding behavior of $P$. sinensis was different depending on the body weight of GAS. The adult $P$. sinensis can swallow the whole apple snails of Class I and Class II because the unbroken snails were found in the gut of $P$. sinensis and a few empty shells remained in aquarium, and this feeding behavior was much like red tilapia Anabastestudineus (Teo, 2006). However, P. sinensis attacked and only ate the softy part of adult snail in Class III and Class IV when the snails sprawled up, and the whole empty shell of GAS remained after turtle attacking in test arena. This feeding behavior was also found in common carp Cyprinuscarpio (Teo, 2006). It is concluded that $P$. sinensis is one of the most hopeful biological agents for GAS because they not only prey the young snails, but also attack the adult ones efficiently.

To control GAS, several effective predators have been introduced into agricultural ecosystem, including various ducks and fishes (Teo, 2001; 2006). Domestic ducks were proven effective for biological control of young GAS in paddy field and could prey equally well under low and high pest population densities (Cowie, 2002). Common carp, Cyprinuscarpio Linnaeus, was also recommended for biological control of GAS in paddy fields after comparing five species of fish (Cowie, 2002). The black carp, Mylopharyngodonpiceus, was an efficient biological control agent of pest snails that bury underground (Ben-Ami and Heller, 2001). However, both fish and duck are impractical for use in rice fields because carp require water deeper than $10 \mathrm{~cm}$, which is too deep for a normal rice field, and keeping ducks in fields requires a lot of care, including feeding every day (Yoshie and Yusa, 2008). In this study, $P$. sinensis showed the strong control capacity on GAS in $Z$. latifolia fields because of their strong predation on GAS and tolerance to starvation. Being different from rice seedlings, $Z$. latifolia can provide more shelter for turtles with a high and tense plant canopy, and $P$. sinensis can grow much well in $Z$. latifolia fields. Furthermore, the technique of stocking $P$. sinensis in $Z$. latifolia field was very easily to be mastered by farmers, rearing turtles required no more extra care as compared to keeping ducks (Yoshie and Yusa, 2008). In conclusion, both laboratory trials and field survey results showed that using $P$. sinensis biologically to control GAS was recommended as an optimal method in wild rice fields infected by GAS.

\section{Acknowledgements}

To Dr. Takashi Wada, at National Agriculture Research Center for Kyushu Okinawa Region, Kumamoto, Japan, for the helpful comments and suggestions on the manuscript. This study was partly supported by $\mathrm{Na}$ tional Key Technology R\&D Program in the 11th Five year Plan of China (Grant No. 2008BADA5B06-1) and Key S\&T Special Project of Zhejiang Province (Grant No. 2004C22003, 2006C12120).

\section{References}

Ben-Ami, F; Heller, J. 2001. Biological control of aquatic pest snails by the black carp Mylopharyngodon piceus. Biological Control 22: 131-138.

Chen, J.M.; Yu, X.P.; Zheng, X.S.; Xu, H.X.; Lu, Z.X.; Zhang, J.F. 2003. Biology of the striped stemborer, Chilo suppressalis Walker fed on Jiaobai, Zizania caduciflora, and rice plants. Acta Agriculturae Zhejiangensis 15: 139-143.

Chen, S.L. 1991. A systematic and evolutionary study of Zizania latifolia. (Gramineae)-gross morphology. Bulletin of Botanical Research 11: 59-73.

Cowie, R.H. 2002. Apple snails as agricultural pests: their biology, impacts, and management. In: Baker, G.M. Molluscs as crop pests. CABI, Wallingford. p. 145-192.

Guo, H.B.; Li, S.M.; Peng, J.; Ke, W.D. 2007. Zizania latifolia Turcz. cultivated in China. Genetic Resources and Crop Evolution 54 1211-1217.

Halwart, M. 1994. The golden apple snail Pomacea canaliculata in Asian rice farming systems: present impact and future threat. International Journal of Pest Management 40: 199-206.

Mochida, O. 1991. Spread of fresh water snails Pilidaemollusca from Argentina to Asia. Micronesica 3: 51-62.

Naylor, R. 1996. Invasions in agriculture: assessing the cost of the golden apple snail in Asia. Ambio 25: 443-448.

Nuangsaeng, B.; Boonyaratapalin, M. 2001. Protein requirement of juvenile soft-shelled turtle Trionyx sinensis Wiegmann. Aquaculture Research 32: 106-111.

Jia, Y.; Yang, Z.; Hao, Y.; Gao, Y. 2005. Effects of animal-plant proteinratio in extruded and expanded diets on nitrogen and energybudgets of juvenile Chinese soft-shelled turtle (Pelodiscus sinensis Wiegmann). Aquaculture Research 36: 6168.

Pan, Y.Y.; Dong, S.Z.; Yu, X.P. 2008. Effects of temperature stress on development, feeding and survival of the apple snail, Pomacea canaliculata (Lamarck). Acta Phytophylacica Sinica 35: 239-244 (in Chinese).

Tang, Q.Y.; Feng, M.G. 2007. DPS ${ }^{\circ}$ Data Processing System: Experimental Design, Statistical Analysis and Data Mining. Science Press, Beijing, China (in Chinese).

Teo, S.S. 2001. Evaluation of different duck varieties for the control of the golden apple snail (Pomacea canaliculata) in transplanted and direct seeded rice. Crop Protection 20: 599604.

Teo, S.S. 2006. Evaluation of different species of fish for biological control of golden apple snail Pomacea canaliculata (Lamarck) in rice. Crop Protection 25: 1004-1012. 
Yoshie, H.; Yusa, Y. 2008. Effects of predation on the exotic freshwater snail Pomacea canaliculata (Caenogastropoda: Ampullariidae) by the indigenous turtle Chinemysreevesii (Testudines: Geoemydidae). Applied Entomology and Zoology 43: 475-482.

Yusa, Y.; Sugiuara, N.; Wada, T. 2006. Predatory potential of freshwater animals on an invasive agricultural pest, the apple snail Pomacea canaliculata (Gastropoda: Ampullariidae), in Southern Japan. Biological Invasions 8: 137-147.

Yu, X.P.; Wada, T.; Li, Z.; Chen, J.M. 2001. Occurrence of golden apple snail, Pomacea canaliculata (Lamarck), in paddy fields and its management. Acta Agriculturae Zhejiangensis 13: 247-252 (in Chinese).
Zhai, C.K.; Lu, C.M.; Zhang, X.Q.; Sun, G.J.; Lorenz, K.J. 2001. Comparative study on nutritional value of Chinese and North American wild rice. Journal of Food Composition and Analysis 14: 371-382.

Zheng, X.S.; Lu, Z.X.; Chen, J.M.; Xu, H.X.; Zhang, J.F.; Chen, L.Z.; Yu, X.P. 2005. Trials of Pomacea canaliculata (Lamarck) control with stocking of soft-shelled turtle. Journal of Zhejiang Agricultural Sciences 1: 61-63 (in Chinese). 